A salt-water aquarium can be a dangerous hobby: A case report of palytoxin intoxication after dermal contact with poisonous coral Peer-reviewed author version

Van Mechelen, M; MESSIAEN, Peter \& VAN DER HILST, Jeroen (2016) A salt-water aquarium can be a dangerous hobby: A case report of palytoxin intoxication after dermal contact with poisonous coral. In: toxicology international, 23(3), p. 276-278.

DOI: $10.22506 / \mathrm{ti} / 2016 / \mathrm{v} 23 / \mathrm{i} 3 / 146726$

Handle: http://hdl.handle.net/1942/29125 


\title{
A salt-water aquarium can be a dangerous hobby: A case report of palytoxin intoxication after dermal contact with poisonous coral
}

\author{
Margot Van Mechelen', Peter E. Messiaen ${ }^{1,2}$, Jeroen C. H. van der Hilst ${ }^{1,2^{*}}$ \\ 'Departments of Infectious Diseases and Immunity, Jessa Hospital, Hasselt, Belgium \\ ${ }^{2} \mathrm{BIOMED}$ research institute, Hasselt University, Hasselt, Belgium \\ *jeroen.vanderhilst@jessazh.be
}

\begin{abstract}
Palythoa toxica is a coral that is often sold to aquarium holders. It contains one of the most toxic substances known to human: palytoxin. It is important for clinicians to recognize this potential lethal intoxication. A 39 year old man presented to the Emergency Department (ED) complaining of rigors, dyspnea, dizziness, atypical chest pain, tremor, and dysarthria. Medical history taking revealed that he was a professional coral dealer. He recalled accidental dermal exposure to mucus of Palythoa toxica four hours before symptoms started. His laboratory tests showed signs of muscular and cardiac damage. He was admitted to the hospital and had a full recovery. Intoxications with palytoxin are potentially lethal. Since the Palythoa coral is often sold to new aquarium holders there is probably an underreporting of cases as many patients and doctors would not link the symptoms to coral exposure. In the setting of an emergency department, physicians should be aware of the symptoms of palytoxin intoxication, including patients with rhabdomyolysis, and ask patients with relevant symptoms about potential contact with corals.
\end{abstract}

Keywords: Palytoxin, zoanith coral intoxication, rhabdomyolysis

Received: 24-05-2016 Revised: 01-08-2016 Accepted: 17-08-2016

\section{Background}

Palythoa toxica are soft colony forming corals that reside in tropical seas around the world. It contains palytoxin, one of the deadliest toxins known to human. Poisonous corals are readily sold in local aquarium stores often without notifying the buyers about the potential toxic effects [1]. Here we present a case report of a patient with palytoxin intoxication after accidental dermal contact with coral from a salt water fish tank.

\section{Case details}

A 36-year old man presented to the emergency departmentbecause of syncope. Three hours earlier he woke upfeeling ill. He had rigors, dyspnea, dizziness, atypical chest pain and noticed a tremor. In addition he suffered from dysarthria. When getting out of bed, he suddenly collapsed and was unconscious for an unknown duration of time. Upon regaining consciousness, he took $500 \mathrm{mg}$ acetaminophen and went back to sleep. Two hours later, he woke up again with similar symptoms and experienced another syncope before deciding to seek medical attention. Medical history at emergency department revealed that the patient is a professional importerof corals from various countries and redistributes them to aquarium stores. The evening before the onset of symptoms he had been manipulating corals of the genus Palythoa toxica. The patient is aware of the dangers of this coral and habitually uses gloves. However, this particular time he forgot his gloves when he lifted a coral out of the water for approximately five seconds. As a defense mechanism the Playtoa toxica produces poison containing mucus. The patient felt the mucus on his skin and immediately washed his hands thoroughly with water

${ }^{*}$ Author for correspondence 
and soap.Upon admission, the blood pressure was122/65 $\mathrm{mmHg}$, heart rate 71 beats/min, with normal oxygen saturation breathing ambient air and a temperature of $36.3^{\circ} \mathrm{C}$.Neurological examination with Romberg's test revealed only a slight deviation to the left . There were no abnormalities at the site of exposure.

Chest X-ray and ECG showed no abnormalities. Initial laboratory results revealed a discrete thrombopenia (145 $\mathrm{x} 10^{\wedge} 9 / \mathrm{L}$, reference range 150-400), leukocytosis (18.8 $\mathrm{x} 10^{\wedge} 9 / \mathrm{L}$, reference range $\left.4.5-11 \mathrm{x} 10^{\wedge} 9 / \mathrm{L}\right)$ with $85.2 \%$ neutrophilia and a CRP of $17 \mathrm{mg} / \mathrm{L}$ (reference range $<5.0$ $\mathrm{mg} / \mathrm{L}$ ).Creatinine kinase (346 U/L;normal <171 U/L) and troponine I $(0.066 \mu \mathrm{g} / \mathrm{L}$; normal $<0.050 \mu \mathrm{g} / \mathrm{L})$ were elevated. A transthoracic echocardiogram pas performed and did not show any abnormalities. While still on the emergency department his neurological symptoms disappeared. The national poisoning information center was contacted and they confirmed that the signs and symptoms of the patient were compatible with palytoxin intoxication.

The patient was admitted to the hospital for observation. After 24 hours all his symptoms had disappeared and thelaboratory analysis showed normalization of creatinine kinase and troponin I. He was discharged during a follow-up period of 3 months he did not experience any cardiac or neurologic symptoms.

\section{Discussion}

Palytoxin is the most deadly nonproteinous toxin for humans ever isolated from nature. The dose at which $50 \%$ of exposed animals die following intravenous administration of palytoxin (LD50) has been shown to be as low as $0.15 \mu \mathrm{g}$ per $\mathrm{kg}$, making it 50 times more toxic than saxitoxin and tetrodotoxin [2]. Palytoxin has a very complex molecular structure that was elucidated by two different groups in 1981[3,4]. The toxin is produced by Palythoa corals, belonging to the family of zoanthids (figure 1). They are common in home aquariums, since they are considered easy to keep and are often recommended to new aquarium owners. They can form large aggregations that often require thinning or removal from the aquarium sincethe corals attach firmly to the surface. Therefore aggressive methods are sometimes required for their removal, including cutting, scraping, applying chemicals, or applying boiling water.It is postulated that the main exposure route to palytoxins is through inhalation of aerosols after pouring boiling water[5]. Although not all zoanthids contain palytoxin, some zoanthids commonly found in home aquariums contain high concentrations of this toxin [1].

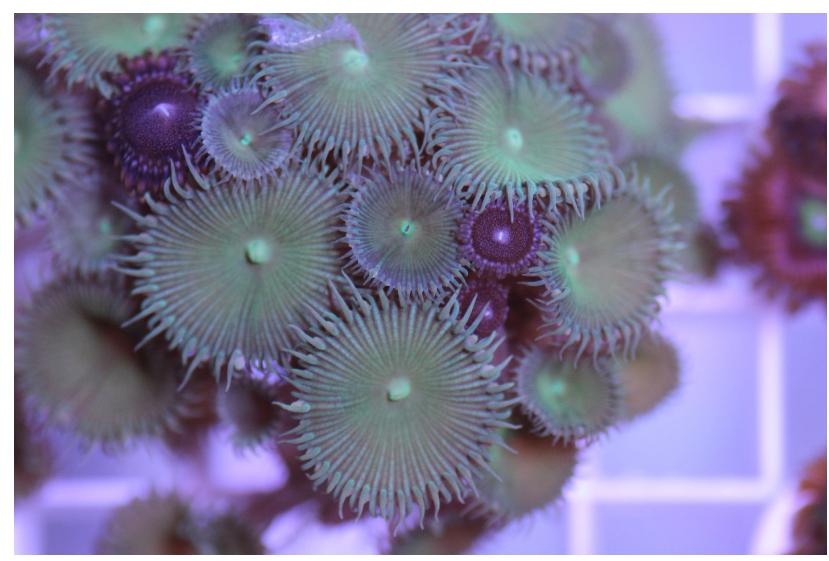

Figure 1. Palythoa toxica.

Palytoxin exerts its toxic effect by binding to $\mathrm{Na} / \mathrm{K}$ ATPase, converting the ion-selective pump into a nonselective cation channel, allowing passive flow of ions following their concentration gradients. The resulting loss of the transmembranic gradient explains why systemic toxicity mainly involves excitable tissue (muscular, cardiac muscle, neurons) [6]. Muscular toxicity presenting as rhabdomyolysis and direct cardiac toxicity a have been described in several case reports[7,8]. Fatal cases of palytoxin intoxications have been describes after ingestion of contaminated sea food[8]. In our patient an elevation of creatinine kinase was seen, but it did not progress to rhabdomyolysis. The mild elevation of troponin I indicates limited myocardial damage. There is no antidote for palytoxin poisoning and treatment consist of supportive measures. In general the toxicity is of short duration (24-48hours), although the sequelae may take weeks to recover.

So far only 6 cases of palytoxin intoxication through dermal contact with poisonous corals have been described in the literature[8]. This is probably an underestimation of the true incidence of palytoxin intoxications. We believe that many intoxications are not recognized. On websites of aquarium enthusiasts palytoxin intoxication is well known and many personal witnesses of intoxication can be found[9]. Palythoa corals are sold in aquarium shops to new aquarium holders without any warning. Our patient was an expert in recognizing corals, linking 
his symptoms himself to the exposure he had the evening before. However, the delay in onset of symptoms and the unfamiliarity to toxic potential makes it difficult for nonexperts to link the symptoms to exposure to corals.In addition, palytoxin affects different organ systems leading to various clinical presentations. So far there are no regulations for importing these dangerous coral neither in the US nor in the EU. Additional warnings should be given to new aquarium owners in order to recognize potential life threatening symptoms at an early stage.

Our case report is limited by inability to detect palytoxin since this test is unavailable in our institution. However, the very typical signs and symptoms, the absence of a differential diagnosis that could explain the multisystem involvement and the temporal relationship between exposure to and onset symptoms makes a diagnosis of palytoxin intoxication highly likely. In the setting of an emergency department, physicians should be aware of the symptoms of palytoxin intoxication, including patients with rhabdomyolysis,and ask patients with relevant symptoms about potential contact with corals.

\section{Conflict of Interest}

None Declared

\section{References}

1. Deeds JR, Handy SM, White KD, Reimer JD. Palytoxin found in Palythoa sp. zoanthids (Anthozoa, Hexacorallia) sold in the home aquarium trade. PLoS One. 2011;6:e18235.

2. Shimizu Y. Complete structure of palytoxin elucidated. Nature. 302:212.

3. Moore RE, Bartolini G. Structure of palytoxin. J. Am. Chem. Soc. American Chemical Society; 1981;103:2491-4.

4. Uemura D, Ueda K, Hirata Y, Naoki H, Iwashita T. Further studies on palytoxin. II. structure of palytoxin. Tetrahedron Lett. 1981;22:2781-4.

5. Hamade AK, Deglin SE, McLaughlin JB, Deeds JR, Handy SM, Knolhoff AM. Suspected Palytoxin Inhalation Exposures Associated with Zoanthid Corals in Aquarium Shops and Homes - Alaska, 2012-2014. MMWR. Morb. Mortal. Wkly. Rep. 2015;64:852-5.

6. Rossini GP, Bigiani A. Palytoxin action on the $\mathrm{Na}(+), \mathrm{K}(+)$-ATPase and the disruption of ion equilibria in biological systems. Toxicon. 2011;57:429-39.

7. Okano H, Masuoka H, Kamei S, Seko T, Koyabu S, Tsuneoka $\mathrm{K}$, et al. Rhabdomyolysis and myocardial damage induced by palytoxin, a toxin of blue humphead parrotfish. Intern. Med. 1998;37:330-3.

8. Tubaro A, Durando P, Del Favero G, Ansaldi F, Icardi G, Deeds JR, et al. Case definitions for human poisonings postulated to palytoxins exposure. Toxicon. 2011;57:478-95.

9. No Title. http://reefbuilders.com/2015/08/26/palytoxin-dangerous/. 